\title{
Five-year publication rate of podium presentations at SICOT Annual Conference: an observational study and new objective proposal of conference power
}

\author{
Khalid Al-Hourani ${ }^{1, *}$, Rami Al-Aref ${ }^{2}$, Robert Ley-Greaves ${ }^{1}$, Fatima Ballout ${ }^{3}$, and Addisu Mesfin ${ }^{4}$ \\ 1 Department of Orthopaedic Surgery, Bristol Royal Infirmary, Upper Maudlin Street, BS2 8HW Bristol, UK \\ 2 Stamford Hospital Columbia University, CT 06902, USA \\ 3 Rush University Medical Center, Chicago, IL 60612, USA \\ 4 Department of Orthopaedic Surgery, University of Rochester Medical Center, Rochester, NY 14618, USA
}

Received 6 December 2016, Accepted 10 March 2017, Published online 17 May 2017

\begin{abstract}
Introduction: The SICOT Conference Committee continually tries to improve the quality of presentations at their annual international meetings. However to the author's best knowledge, no previous study has been undertaken to determine abstract quality. This study aimed to determine the five-year publication rate of presentations made at the 2009 SICOT Annual International Conference (AIC), recognise predictors of fulltext publication, identify inconsistencies between presentations and publications, and determine presentationpublication delay.

Methods: We retrieved all 329 oral presentation abstracts from the 2009 SICOT Conference, recorded fundamental study details and conducted a comprehensive, electronic search of Medline and PubMed to determine publication status. For subsequent publications, we examined for inconsistencies between presentation abstracts and full-text publications, whether there were retrospectively identifiable publication predictors and calculated presentation-publication delay.

Results: The five-year publication rate for all presentations was $31.3 \%$, for oral presentations. The average presentation-publication delay was 23.4 months. Observational studies were the most commonly published studies. Publications most commonly resulted from studies related to hip and knee subspecialties.

Conclusion: Our study shows that almost one third of all abstracts presented at SICOT led to a full-text publication. This is a positive outcome particularly when made in comparison to similar studies of other reputable international conferences such as European Federation of Orthopaedics and Traumatology (EFORT) and American Academy of Orthopaedic Surgeons (AAOS). This study re-enforces SICOT's reputation as a world leading international conference with a strict peer-review process yielding high-quality presentations.
\end{abstract}

Key words: Conference, Publication, Rate, SICOT, Podium, Presentation.

\section{Introduction}

International conferences remain an excellent way of disseminating research and furthering evidence-based medicine, thereby potentially influencing clinical practice. Abstracts presented at conferences also provide a forum for debate, critical analysis and discussion, which in itself is a form of peer review. Previous studies have suggested up to $63 \%$ of major orthopaedic textbook chapters having included results from abstracts presented at international orthopaedic meetings [1]. However, abstracts in themselves are not always readily searchable postpresentation and this can lead to difficulties in

\footnotetext{
*Corresponding author: kalhourani@doctors.org.uk
}

citing any evidence presented at meetings. A peer-reviewed publication therefore remains the gold standard when judging the quality and validity of a study.

The International Society of Orthopaedic Surgery and Traumatology (SICOT) holds an annual international conference that provides a well-known and important forum to share novel research findings. There is therefore great emphasis on conferences such as this in providing a substantial portion of continued medical education for surgeons and allied health professionals. The SICOT Programme Committee is responsible for the selection of podium presentations as part of a strict, blinded and peer-reviewed process. This process has led to podium presentations at this meeting becoming increasingly well regarded, and the knowledge acquired as a result of these 
presentations is becoming more rapidly incorporated into clinical practice. For this reason, it is essential to question the validity of such podium presentations.

Our aim was therefore to: (1) evaluate the five-year publication rate of podium presentations of SICOT Annual International Conference, (2) to evaluate the consistency of abstracts presented and subsequent consistency with the full peer-reviewed publication and (3) to discuss our findings with other well-known orthopaedic international conferences.

\section{Materials and methods}

We reviewed all podium presentations at the 2009 SICOT XXV Triennial World Conference in Prague, Czech Republic. The abstracts from the 2009 SICOT Conference were chosen in order to give at least five years for subsequent publications and as it also allows the methods to fall in line with those used in previous similar studies [1-4]. All 329 podium presentations published in the 2009 SICOT Conference podium abstract book were included in the study. Poster abstracts were excluded due to a higher scientific value being placed on podium presentations.

The Bhandari methodology previously described was the main strategy used to search for abstracts in PubMed and Medline [1]. We used two separate reviewers to search for abstracts in order to increase reliability. Any abstracts, which were not agreed upon by the two reviewers, were reviewed by the first author in order to come to a majority decision. Comparing the abstract and final publication through similarity of content provided the basis for inclusion. This only comprised a small minority of the overall number.

A sizeable database was created for data input and final analysis. Each study was given a unique identification number and a variety of data were recorded for each study including study design, methodology, statistical analysis and study outcomes. All analysis was done using GraphPad Prism statistical analysis software. A median (range) value was obtained for time to publication and number of centres involved in each study. Journal impact factors were sorted accordingly in the database to rank the highest and lowest impact factor journals in which a publication occurred. The database was sorted by journal title to provide overall journal ranking in terms of number of published abstracts. A similar method was used to rank subspecialties published, type of study, country and associated level of evidence according to the Oxford Centre for Evidence-Based Medicine grading system. A goodness-of-fit test was used to assess correlation between parameters and publication, with publication set as a binary figure of either 1 (indicating publication) or 0 (indicating no publication). Differences in study parameters such as between the presented abstract and a final publication were recorded for analysis. These parameters included methodology, study size, number of centres involved as well as primary and secondary outcomes. A difference would be described as any significant change in these parameters between abstract and final publication. Consistency was therefore measured as a mean percentage with an attributed
Table 1. Showing the top 10 journals in rank order of papers published.

\begin{tabular}{llc}
\hline $\begin{array}{l}\text { Ranking (number } \\
\text { published) }\end{array}$ & \multicolumn{1}{c}{ Journal } & $\begin{array}{c}\text { Impact } \\
\text { factor }\end{array}$ \\
\hline $1(9)$ & $\begin{array}{l}\text { International Orthopaedics } \\
2(7)\end{array}$ & 2.387 \\
$3(5)$ & $\begin{array}{l}\text { Journal of the Medical Association } \\
\text { of Thailand }\end{array}$ & 0.314 \\
& $\begin{array}{l}\text { Journal of Orthopaedics and } \\
\text { Traumatology }\end{array}$ & 1.777 \\
$4(5)$ & Journal of Foot and Ankle Surgery & 0.845 \\
$5(5)$ & Indian Journal of Orthopaedics & 0.64 \\
$6(5)$ & Acta Orthopaedics Belgica \\
$7(4)$ & Clinical Orthopaedics \& Related & 0.629 \\
& $\quad$ Research \\
$8(4)$ & Orthopaedics & 1.765 \\
$9(3)$ & Spine & 2.256 \\
$10(3)$ & Journal of Paediatric Orthopaedics & 1.163 \\
\hline
\end{tabular}

confidence interval. If there was no eventual publication then only information on the abstract was collected.

\section{Results}

Three hundred and twenty-nine abstracts were podium presentations at the 2009 International Society of Orthopaedics and Traumatology (SICOT). From these, 103 (31.3\%) were published with a complete report with a median time to publication of 23.4 months (0-72 months). The 103 papers were published in 45 distinct journals. The most commonly published subspecialties were paediatric orthopaedics, hip and knee arthroplasty. A breakdown of the top 10 journals in which these papers were published and their respective impact factors are shown in Table 1. The median (range) impact factor score of the journals, which published the podium research, was 1.730 (0.181-19.967). The journal, in which an abstract was published, with the highest impact factor was The British Medical Journal (impact factor 19.967), with the lowest impact factor journal being The European Journal of Orthopaedic Surgery and Traumatology (impact factor 0.181).

\section{Characteristics of abstracts published}

The majority of published abstracts were submitted from single centre institutions with a median of 1.12 (1-3) with some multicentric publications. Sample sizes ranged from a minimum of two to a maximum of 15646 with a median of 43. The largest number of studies submitted to SICOT was from India with $12.2 \%$, while Thailand was the most published country with $16.0 \%$ of all completed publications (Tables 2 and 3, respectively). Moreover, the United States had the highest ratio of submitted to publish with a ratio of $63.6 \%$ (11 submitted to SICOT and seven publications achieved). Interestingly, both sample size and subspecialty of the abstracts submitted were not significant when tested using chi-squared goodness of fit $(p>0.05)$ and therefore likely played no role in successful publication of the submitted abstract. 
Table 2. Showing the top five countries with presented oral abstracts. Total $N=329$.

\begin{tabular}{llc}
\hline Ranking & Country & Number (\%) \\
\hline 1 & India & $40(12)$ \\
2 & Thailand & $36(11)$ \\
3 & Russia & $30(9)$ \\
4 & Japan & $22(7)$ \\
5 & Korea & $21(6)$ \\
\hline
\end{tabular}

\section{Study methodology}

We found that the dominant research design was observational comprising $81.8 \%$ of all submitted papers. Moreover, of the abstracts that were eventually published, Retrospective observational studies were also the primary research design accounting for $77.7 \%$ of all published papers and these were all level III evidence. Randomised control trials (level I evidence) consisted of only $1.5 \%$ and $1.1 \%$ of submitted and published articles, respectively. Of the presented abstracts, 78.4\% mentioned clear statistical methods, while $88.3 \%$ of the abstracts that were published contained clear statistical methods signifying a potential benefactor in abstracts that proceed to full publication. The median (range) level of evidence of all studies was 3 (1-5) which corresponds to most studies being a mix of prospective and retrospective.

\section{Consistency of abstracts with final publication}

We identified seven major categories to compare the consistency between the submitted abstract and the eventual completed full publication. These categories include precision variances, change in hypothesis/study objective focus, differing study design, variation in sample size, changes in statistical analysis, and differing primary and secondary outcomes. The most consistent categories were the hypothesis and study design categories with mean consistency of $90.4 \%$ (CI 82.6\%, 95.5\%) and 88.3\% (CI 80.0\%, 94.0\%), respectively. The least consistent category was sample size with a mean of 69.2\% (CI 58.8\%, 78.3\%). Precision studies and statistical analysis remained fairly consistent with means of $81.9 \%$ (CI 72.6\%, 89.1\%) and 77.7\% (CI 67.9\%, 85.6\%), respectively. Lastly primary and secondary outcomes also remained consistent with corresponding means of $87.2 \%$ (CI 78.8\%, 93.2\%) and $85.1 \%$ (CI 76.3\%, 91.6\%).

\section{Discussion}

The International Society of Orthopaedics and Traumatology (SICOT) is a highly regarded conference that is dedicated to the discussion and dissemination of all orthopaedic topics. Since its initiation in 1929 it has had 37 annual international conferences. Podium and paper presentations undergo a strict peer-review process and are considered high quality, however it is important to analyse this objectively through publication
Table 3. Showing the top five countries with abstracts proceeding to full publication. Total $N=103$.

\begin{tabular}{llc}
\hline Ranking & \multicolumn{1}{c}{ Country } & Number (\%) \\
\hline 1 & Thailand & $17(16)$ \\
2 & India & $13(13)$ \\
3 & France & $9(9)$ \\
4 & United States of America & $7(7)$ \\
5 & United Kingdom & $6(6)$ \\
\hline
\end{tabular}

rates as this represents a permanent, accessible and validated representation of the scientific abstract.

Rates of full publication of presented abstracts range widely in the literature from $11 \%$ to $78 \%[1,2,8,9]$. Our study is the first to analyse the SICOT Annual International Conference. We have demonstrated a five-year publication rate of $31.3 \%$, which is consistent with other high profile conferences such as AAOS (34\%). Furthermore of those published, we reported mean time to publication of 23.4 months, which falls in line with other notable conferences such as AAOS and EFORT.

It is reassuring to note such a high consistency between abstract and full publication with regard to study hypothesis and study designs which is a direct reflection of aims and methods. With regard to the least consistent category of study sample size, this is often owed to the fact that studies are amended following feedback from audience members' postpresentation [10]. Observational studies remain the most popular category of study, however, there remains a clear lack of level 1 randomised control trials presented at this meeting. Future work should include re-analysing more recent conferences to monitor any trends.

There are a number of reasons why presented abstracts may not achieve full publication. This includes failure to submit as a full article, pessimism about chances of an article being accepted and rejected by journals through the peerreview process. It is also likely that we have underestimated the publication rate of SICOT as we conducted a PubMed and Medline search and therefore publications not indexed in these databases would be missed. However, these remain highly popular databases for research articles and therefore are the databases most likely to reach the majority of our audience. One further possible limitation is that we have limited our search to a five-year period after presentation in 2009. While the authors recognise some studies could be published after five years, there is evidence to suggest that the majority of papers are published within four years of presentation [5-7].

To conclude, this is the first study to analyse this world renowned international conference and has demonstrated results comparable with those of other notable conferences of a similar standard. Since 2009, annual submissions to SICOT have steadily increased and we would expect podium presentations to be of an even higher scientific value and subsequently an even higher publication rate in recent years. The authors propose another analysis to confirm this hypothesis and we propose a new objective conference grading system based on the publication rate. 


\section{Compliance with ethical standards}

\section{Conflict of interest}

On behalf of all authors, the corresponding author states that there is no conflict of interest.

\section{Funding}

There is no funding source.

\section{Ethical approval}

This article does not contain any studies with human participants or animals performed by any of the authors.

\section{Informed consent}

Not applicable.

Acknowledgements. The authors would like to thank Kamal Shihadeh for his statistical advice.

\section{References}

1. Bhandari M, Devereaux PJ, Guyatt GH, Cook DJ, Swiontkowski MF, Sprague S, Schemitsch EH (2002) An observational study of orthopaedic abstracts and subsequent full-text publications. J Bone Joint Surg Am 84(4), 615-621.
2. Kwong Y, Kwong FN, Patel J (2007) Publication rate of trauma abstracts presented at an international orthopaedic conference. Injury 38(7), 745-749.

3. Donegan DJ, Kim TW, Lee GC (2010) Publication rates of presentations at an annual meeting of the American Academy of Orthopaedic Surgeons. Clin Orthop 468(5), 1428-1435.

4. Amirhamzeh D, Moor MA, Baldwin K, Hosalkar HS (2012) Publication rates of abstracts presented at pediatric orthopaedic society of North America meetings between 2002 and 2006. J Pediatr Orthop 32(2), e6-e10.

5. Riordan FA (2000) Do presenters to paediatric meetings get their work published? Arch Dis Child 83(6), 524-546.

6. Roy D, Sankar V, Hughes JP, Jones A, Fenton JE (2001) Publication rates of scientific papers presented at the Otorhinolarygological Research Society meetings. Clin Otolaryngol 26(3), 253-256.

7. Scherer RW, Dickersin K, Langenberg P (1994) Full publication of results initially presented in abstracts: a meta-analysis. JAMA 272(2), 158-162.

8. Okafor L, Frost C, Mesfin A (2015) Publication rate of podium presentations from CSRS Annual Meeting. Spine 40, 699-702.

9. Frost C, Rubery P, Mesfin A (2015) Publication rate of podium presentation at two international spine meetings: SRS and IMAST. Spine Def 3, 528-532.

10. Bakkum BW, Chapman C, Johnson C (2014) Publication rates of abstracts presented at the Association of Chiropractic Colleges Educational Conference/Research Agenda Conference from 2002 to 2008. J Chiropr Edu 28, 32-40.

Cite this article as: Al-Hourani K, Al-Aref R, Ley-Greaves R, Ballout F \& Mesfin A (2017) Five-year publication rate of podium presentations at SICOT Annual Conference: an observational study and new objective proposal of conference power. SICOT J, 3,36 